\title{
EFFECTS OF HYPERTRIGLYCERIDAEMIA ON BLOOD COAGULATION FACTOR VII : A CASE CONTROL STUDY OF 110 CASES
}

\author{
Rehana Aziz ${ }^{1}$ ASM Towhidul Alam ${ }^{2}$ Ajoy Deb ${ }^{3}$ Mahmudul Haque ${ }^{4}$
}

\begin{abstract}
Summary
The study was designed to observe the effects of hypertriglyceridaemia on blood coagulation factor VII (FVII). In this study IIO individuals were included based on defined criteria. They were grouped as hypertriglyceridaemic (case) and normotriglyceridaemic group (control). Inclusion criteria for both case and control were nonsmokers, non-alcoholics, non-diabetics and exclusion criteria for both the groups were diseases like nephrotic syndrome, diabetes mellitus, liver diseases, hypothyroidism, hyperthyroidism and obesity. Subjects having on medicines like steroids, anticoagulant therapy were also excluded from the study:

The study was carried out in the Department of Biochemistry of Bangubandhu Sheikh Mujib Medical University (BSMMU) and in the Department of Hematology of Armed Forces Institute of Pathology (AFIP) of Dhaka Cantonment, Dhaka. Blood coagulation factor FVII of both hypertriglyceridaemic subjects as well as normotriglyceridaemic individuals was estimated and the results were compared between the two groups.

The mean $\pm S D$ values of triacylglycerol in cases $(n=60)$ and of control $(n=50)$ was $360.8 \pm 52.72$ and $142.50 \pm 36.88$ respectively:

The mean $=S D$ values of plasma coagulation factor VII coagulant activity of cases and of control was $89.5 \pm 12.75$ and $69 \pm 7.36$ respectively which is significantly higher than that of control.

In this study a strong co-relation was observed between plasma triacylglycerol (TG) and plasma coagulation factor FVI, which suggests increased TG level may augment the factor FVII coagulant activity:
\end{abstract}

Key words: Hypertriglyceridaemia; plasma coagulation factor VII; hypercoagulability; coronary artery disease

1. Assistant Professer of Biochemistry Chittagong Medisal College, Chittagong

2. Associate Professor of Biochemistry Chittagang Medical College, Chittagong

3. Lecturer of Biochemistry Chittagong Medical College, Chittagong

4. Professor of Biochemistry Chittagong Medical College, Chittagong

Correspendence: Dr Rehana Aziz

\section{Introduction}

Coronary artery discase (CAD) is a leading cause of morbidity and mortality. The prevalence of CAD is increasing day by day with changing life style. Lipids and lipoproteins are major risk factors associated with cardiovascular disease ${ }^{1}$. Seyeral factors play a role in the pathogenesis of hypertriglyceridaemia including fatty diets. increased bodyweight, genetic influence, either increased plasma glucose concentrations or insulin deficiency ${ }^{2}$. Lack of physical activity increases serum TG concentration ${ }^{3}$. Metabolic disorders like diabetes mellitus, hypothyroidism and nephrotic syndrome are associated with hypercholesterolemia and hypertriglyceridaemia ${ }^{4}$. Hypertriglyceridaemia occurs as complication of steroid therapy $y^{2}$. There is a strong association among lipids especially TG rich lipoproteins and haemostatic factors like fibrinogen, FVII, FX, Plasminogen activator inhibitor-1 (PAI-1) and fibrinolytic activity 4 . In hypertriglyceridaemia there is increased level of plasma coagulation factors- fibrinogen, FVII, FX and decreased fibrinolytic activity ${ }^{5}$. Studies have shown that fibrinogen, activated coagulation factor FVII, spontaneous platelet aggregation and elevated level of plasminogen activator inhibitor-1 are all associated with $\mathrm{CAD}^{6}$

It has increasingly been recognized that thrombogenesis contributes to nearly all deaths are due to $\mathrm{CAD}^{7}$. Thrombogenesis is directly related to serum TG level and blood coagulation factor FVII, FX, fibrinogen. Hypertriglyceridaemia may be designated when there is persistent rise of fasting triacylglycerol above normal level. Desired level of fasting triacylglycerol is below $200 \mathrm{mg} / \mathrm{dl}^{8}$. As a working role the desired level of serum triacylglycerol concentration is $<2.2 \mathrm{mmol} / \mathrm{L}$ or $<$ $200 \mathrm{mg} / \mathrm{dl}^{9}$.

Coagulation factor FVII in its two chain activated form (FVIIa) and in association with adequate amount of tissue factor (TF), is a potent trigger of coagulation and its elevation could contribute to a hypercoagulable state, thus increasing the susceptibility to thrombosis ${ }^{10}$. High circulating levels of FVII are known to be associated with elevated concentrations of blood lipids. More specifically hypertriglyceridacmia is correlated with raised FVII coagulant activity ${ }^{11}$. The concept of "increased thrombotic tendency" and of "hypercoagulability" defined as increased rate of in vivo thrombin generation are therefore relevant to the pathogenesis of $\mathrm{CAD}^{12}$,

The aim of this study was to observe the effects of hypertriglyceridaemia on blood coagulation factor F VII. 


\section{Materials and methods}

A cross sectional comparative study. Plasma coagulation factor FVII and serum triacylglycerol of 110 men age ranging from $30-55$ years with known history of hypertriglyceridemia but no history of diabetes mellitus, alcohol consumption and smoking were estimated and compare with the results of normotriglyceridaemic individuats.

After an overnight fast ( $8-10 \mathrm{hrs}) 6 \mathrm{ml}$ of venous blood was drawn from the median cubital vein with a disposable syringe with all aseptic precaution. About $1.8 \mathrm{ml}$ of blood was transferred in a test tube containing $0.2 \mathrm{mI}$ anticoagulant $(3.2 \%$ tri-sodium citrate) and centrifuged. After separation of plasma. functional activity of FVII was estimated within 6 hours of collection of blood by using Quick's onestage prothrombin time. Rest of blood was taken in a separate test tube and allowed to form clot. After formation of clot, blood was centrifuged and serum was separated and serum triacylglycerol was estimated by enzymatic method.

\section{Results}

Mean \pm SD of age in years of cases and control was $41.23 \pm 7.78$ and $38.65 \pm 5.91$ respectively. No significant difference was observed between the two groups shown in Table 1 .

Table I

\begin{tabular}{llll}
\hline Groups & Mean age (in years) & \pm SD & 'p' value \\
\hline Cases $(\mathrm{n}=60)$ & 41.23 & 7.78 & \\
& & & $>0.05$ \\
Control $\mathrm{n}=50)$ & 38.65 & 5.91 &
\end{tabular}

Mean \pm SD of Triacylglycerol $(\mathrm{mg} / \mathrm{dl})$ of cases and control was $360.8 \pm \$ 2.72$ and $142.50 \pm 36.88$ and Mean \pm SD of Coagulation factor FVIl of cases and control was $89.5 \pm 12.75$ and $69 \pm 7.35$ respectively. In this study TG and coagulation factor-VII (activity in $\%$ ) level was significantly higher in cases than control ( $\mathrm{p}$ ' $<0,001)$ shown in Table II.

\section{Table II}

\begin{tabular}{llll|}
\hline Parameters & $\begin{array}{l}\text { Mean } \pm \text { SD } \\
\text { (Control) }\end{array}$ & $\begin{array}{l}\text { Mean } \pm \text { SD } \\
\text { (Cases) }\end{array}$ & 'p' value \\
\hline TG in mgdl & $142.50 \pm 36.88$ & $360.8 \pm 52.72$ & $<0.001$ \\
Factor-VII & $69 \pm 7.35$ & $89.5 \pm 12.75$ & $<0.001$ \\
(Activity in \%) & & & \\
\hline
\end{tabular}

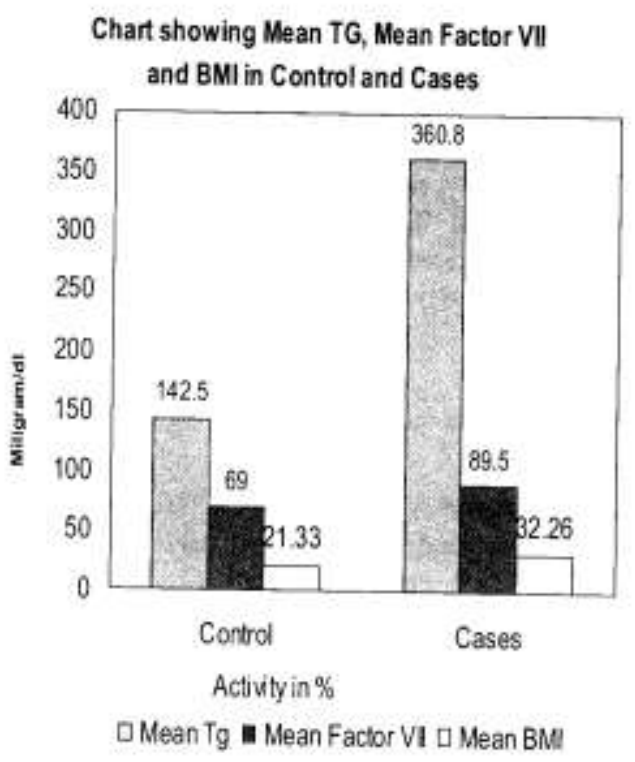

\section{Discussion}

Hypertriglyceridaemia is one of the commonest lipoprotein abnormalities found in general population and patients after myocardial infaretion ${ }^{23}$ and some studies suggested that plasma triacylglycerol is an independent risk factor for ischemic heart disease (IHD) ${ }^{14}$. Plasma coagulation FVII activity in $\%$ in cases was $89.5 \pm 12.75$ and that of control was $69 \pm 7.35$. The statistical difference is significantly higher in cases than control ( unpaired ' $\mathrm{t}$ ' test $\mathrm{p}<0.001$ ). The mean triacyglycerol in cases was $360.8 \mathrm{mg} / \mathrm{dl}$ which is significantly higher than that of control ( $p<0.001$ ).

A co-relation was found that more the triacyglycerol more is the coagulant activity of FVII in this study. It is also observed that Mean body mass index (BMI) was higher in cases than control group.

Fibrinogen, FVIIc and FXc levels appeared to be higher among the hypertriglyceridemic subjects ${ }^{15}$. Raised level of clotting factors VIIc, VIIIc, Xe and fibrinogen were implicated as a components of a possible "hypercoagulable state"16.

FVII is also an independent risk factors for CAD or recurrent myocardial infaretion (MI) ${ }^{17}$. High levels of TG in association with FVII hyperactivity and arising from an increase in total circulating FVII might dispose hypercoagulability and thus to a prethrombotic state ${ }^{12}$. Therefore this study emphasizes the role of hypertriglyceridemia in the pathphysiological mechanism of hypercoagulability and thus causing $\mathrm{CAD}$. 


\section{Conclusion}

Increased level of plasma coagulation FVII in this study population with hypertriglyceridaemia as observed may play a significant role in the possibility of coronary thrombosis. Effective control of hypertriglyceridaemia will contribute to the prevention of IHD in all individuals whenever hypertriglyceridacmia is detected. However a large scale study may help us to come to a definite conclusion.

\section{Disclosure}

All the authors declared no competing interestes.

\section{References}

1. Carlson LA and Bottiger LF. Ischemic Heart Disease in relation to fasting values of plasma triglycerides and cholesterol. Stockholm Prospective Study, Lancet 1972; April 22: 865-868

2. Tzaoumis M. Triglycerides in clinical medicine. Am.J.Clin.Nutr.1978;31:1437-1452

3. Rifkind BM, Begg T.Relationship betwwen relative bodyweight and serum lipids. BMJ 1966;295:246-247

4. Mayes PA. Cholesterol synthesis, transport and excreation. Harpers Biochemistry. 24th edn.1996; chapter 28, 271. Simon and Schuster company

5. Fuster V, Badimon L, Badimon JJ and Chesbro $\mathrm{JH}$. The pathogenesis of coronary artery disease and the acute coronary syndrome. N Eng J Med 1992; $326: 342-50,310-318$

6. Hamsten A, Wiman B, Faire dU, Blomback M. Increased plasma levels of a rapid inhibitor of t-PA in young survivors of MI. N Eng J Med 1985; 313:1557-1563

7. Simpson HCR, Chakrabarti R, Meade TW, Stirling Y, Woolf L, Mann J. Hypertriglyceridaemia and Hypercoagulability, Lancet 1983; April9; 786-790

8. Meade TW, Chakrabarti R, North W R S, Stirling Y. Thompson S G, Haines A P. Haemostatic function and cardiovascular death; early results of a prospective study. Lancet 1980; May 17: 1050-1054
9. Stein EA, Myers GL. Lipids, Lipoproteins, and Apo-lipoproteins.Teitz Text Book of Clinical Chemistry.2nd edn. 1994; 1002-1081.W.B. Saunders Company, Philadelphia

10. Isselbacher KJ, Braunwald E., Wilson JD, Martin JB, Fauci AS, Kasper DL. Harrison's Principle of Internal Medicine. 14th edn. 1998; 2: 2059-2069

11. Collen D and Linjen H R. Basic and clinical aspects of fibrinolysis and thrombolysis. Blood. 1991; $78: 3114$

12. Mitropoulos K A. Hypercoagulability and factor VII in hypertriglyceridemia. Seminars in thrombosis and haemostasis 1988: $14: 246-252$

13. Meade TW, Chakrabarti R, Haines AP, North WRS, Stirling Y. Hacmostatic, Lipid and blood pressure profiles of women on oral contraceptives containing $50 \mathrm{mg}$ or $30 \mathrm{mg}$ estrogen. Lancet. 1977 ; 11: $948-951$

14. Meade T W, Mellows S, Brozovic M, Millar G J, North W R S, Stirling Y, Chakrabarti R, Thompson S G, Haines A P, Imeson J D. Haemostatic function and ischemic heart disease; Principal results of the Northwick Park Heart study. Lancet 1986; September 6: 533-537

15. Gustafson A, Elmfeldt D, Wilhelmsen I, Tibblin G. Serum lipids and lipoproteins in men after myocardial infarction compared with representative population sample. Circulation 1972; 46: 709-716

16. Jacques G Jr and Jeffrey SC. Clustering of cardiovascular risk factors: Targeting High-risk individuals. Am J cardiol 1991; 76;8A-20A

17. Anderson P. Hypercoagulability and reduced fibrinolysis in hypertriglyceridaemia: relationship to metabolic cardiovascular syndrome, J-cadiovascpharmacol 1992; 20 suppl 8; S 29-31 